\title{
Mosquitoes as pesticide pollution Indicators: A comparative susceptibility analysis of field and laboratory strains of mosquitoes against different conventional insecticides
}

\author{
Asha Ambadath Velayudhan ${ }^{1,2}$, Lakshmi Kalarikkal Venugopalan ${ }^{1,2}$, Sudhikumar Ambalaparambil Vasu', \\ Aneesh Embalil Mathachan ${ }^{3 *}$ \\ ${ }^{1}$ Department of Zoology, Christ College, Irinjalakuda, Thrissur, Kerala, India. \\ ${ }^{2}$ Department of Zoology, St. Joseph's College, Irinjalakuda, Thrissur, Kerala, India. \\ ${ }^{3}$ Department of Zoology, University of Calicut, Malappuram, Kerala, India.
}

\begin{tabular}{l}
\hline ARTICLE INFO \\
\hline Article history: \\
Received on: March 19, 2021 \\
Accepted on: June 28, 2021 \\
Available online: November 10, 2021 \\
\hline
\end{tabular}

\section{Key words:}

Kole Wetlands, mosquitoes, pesticide pollution, susceptibility, indicators

\begin{abstract}
Thrissur Kole wetlands fall under the category of temporary wetlands that are exceedingly ideal procreation environments for mosquitoes. A broad array of insecticides is used as a competitive weapon in mosquito restriction tactics, including organochlorines, organophosphates, carbamates, and pyrethroids. Indiscriminate use of these chemicals could develop resistance in targeted and nontargeted species present in that environment. The present study is an assessment of the susceptibility status of laboratory and field strain Aedes albopictus and Culex quinquefasciatus mosquitoes against deltamethrin, lambda-cyhalothrin, and malathion employing the World Health Organization protocol. The results show that laboratory strain mosquitoes are more susceptible than the field-collected mosquitoes toward these insecticides. The field strain of Ae. albopictus showed $6.36,11.74$, and 18.36 times resistance than the laboratory strain against malathion, deltamethrin, and lambda-cyhalothrin, respectively. $C x$. quinquefasciatus larvae also repeated this resistance pattern like 4.54 times resistance against malathion and 13.15 times and 12.62 times resistance against deltamethrin and lambdacyhalothrin, correspondingly. The increased susceptibility of the field strain could also lead to a prospect of treating mosquitoes as an indicator species of pesticide contamination. Finding out the precise dosage of insecticide applications could furthermore help in the vector management program and diminish environmental pollution caused by these chemicals.
\end{abstract}

\section{INTRODUCTION}

Wetlands are inimitable waterlogged ecosystems with distinctive abiotic and biotic environmental characteristics. These aquatic systems might support the massive quantity of floral and faunal diversity concerning their origin, topographical position, aquatic organization, and interaction among them [1]. As stated by a public health organization, wetlands are considered favorable procreation grounds for vector mosquitoes transmitting arboviruses and parasites [2,3]. Thrissur Kole wetlands is a shallow-water lowlying strip of the aquatic system acting as an intermediary region between terrestrial and marine ecosystems, which is maintained at

\footnotetext{
*Corresponding Author

Aneesh Embalil Mathachan, Department of Zoology, University of Calicut, Calicut university P O, Malappuram District, Kerala, 673635, E-mail: aneeshembalil@gmail.com
}

$0.5-1 \mathrm{~m}$ under sea level. These Ramsar sites are topographically located in the central region of Kerala, which overlays an area of 10,187 ha and spreads across Mukundapuram, Chavakad, and Thrissur Taluks of Thrissur district. Kole lands are inundated around half of the year with monsoon water dispensed by the two major rivers in Thrissur, and in the next half of the year, paddy as well as vegetable cultivation is practiced [4]. Byproduct deposition by agriculture could modify the depth and parameters of the water system, and these favorable changes might provide a reproducing environment for mosquitoes. For example, declining water temperature led to vector species development $[5,6]$.

Many parasites and arboviruses that are causative for diseases like malaria, dengue, chikungunya, zika, filariasis, yellow fever, Japanese encephalitis, etc. have accomplished association with some mosquitoes to disperse their pathogenicity. Mosquito-borne diseases are considered one of the primary reasons for mortality 
and illness around the globe, especially in tropical and subtropical countries. Apart from the disease transmission, mosquitoes are the most annoying human pests with their irritating bloodfeeding behavior [7,8]. Anopheles, Aedes, and Culex are the three major genera that comprise disease-spreading vector mosquitoes [9]. Cx. quinquefasciatus is one of the most annoying common mosquito species [10]. This mosquito can carry a nematode called Wuchereria bancrofti which cause filariasis, West Nile virus, Saint Luis encephalitis virus, Ross river virus, and Japanese encephalitis virus across the Earth [11-15]. Ae. albopictus is an indigenous species in Southeast Asia; hence, the name Asian tiger mosquito, which is spread all over the world. It has the potential vectorial capacity to transmit chikungunya, dengue, and some other west Nile viruses $[16,17]$.

Mosquito-borne diseases substantially provide infection load, mortality, poverty, and devitalization to the society in tropical countries where the disease has been dispersed [9]. Over the past few years, unusual disease occurrence and severe annoyance were frequent in infected areas; hence, scientists have found out that mosquito control would be the most appropriate solution for this puzzle [18]. Chemical treatment leftovers as the primary indispensable tactic are used in pest management because of their rapid results in the broad treatment area [19]. Adequate insecticide practice is regarded as an influential defense to achieve better public health manifestations and increase agricultural yield in developing countries [20-22]. From the beginning of pest management programs, insecticide-based mosquito eradication operations could be assessed as the highly efficient approach, but only a limited number of less harmful and highly economical insecticides are used in these practices [23].

Malathion is a chemical compound in the organophosphate insecticide family, which is chemically formed by the esterification of thiophosphoric acid and phosphoric acid. These substances are regarded as neurotoxins due to their detrimental effect on a neurotransmitter called acetylcholine and are mainly used in the pest management program. A group of synthetic insecticides is also used in mosquito control, namely pyrethroids, which contains deltamethrin, lambda-cyhalothrin, permethrin, etc. Pyrethroids act on the nervous system of targeted organisms similar to organophosphate, but instead of the neurotransmitter, pyrethroids can influence the sodium channels of neurons [24,25]. Malathion and pyrethroids are widely used in mosquito management in the public health domain. However, its prolonged and excessive use led to a considerable degree of chemical resistance in the targeted organisms [26]. Screening of insecticide susceptibility and dosage estimation can help in vector control operations and the evaluation of insecticide influence on mosquito behavior [27].

\section{METHODOLOGY}

\subsection{Study Site}

Thrissur Kole wetlands is a 10,187 ha area located between $10^{\circ} 20^{\prime}$ and $10^{\circ} 40^{\prime} \mathrm{N}$ latitude and between $75^{\circ} 58^{\prime}$ and $76^{\circ} 11^{\prime}$ E longitude in Kerala's central region. Thrissur Kole wetlands extend across Mukundapuram, Chavakad, and Thrissur Taluks of Thrissur district. This area spreads from Velukara in the south to the northern bank of Chalakudy river and Tholur and Kaiparambu areas of Thrissur Taluk in the north. The following wetland area of Thrissur Taluk is named Ponnani Kole. The significant breeding habitats of mosquitoes in Kole wetlands comprise paddy fields, rocky pools, tree holes, coconut shells, ditches, containers, irrigation canals, and ponds [28].

\subsection{Insecticide}

Lambda-cyhalothrin, deltamethrin, and malathion (technical grade) were purchased from "New India Surgicals", Calicut, Kerala, India.

\subsection{Mosquito Sampling and Colony Maintenance}

Ae. albopictus and $C x$. quinquefasciatus mosquitoes were collected from different Thrissur Kole wetlands' localities and identified by classical taxonomic methods [29,30]. The collected larvae were reared into adults in laboratory conditions (temperature $26 \pm 2{ }^{\circ} \mathrm{C}$, larval food was prepared by mixing yeast and dog biscuits). Adult mosquitoes were fed with 5\% sucrose and blood meal was provided on the third day of emergence. F1 progeny larvae of field-collected mosquitoes were subjected to larval bioassay. Laboratory colonized insecticide-free Ae. albopictus and Cx. quinquefasciatus were maintained in the communicable disease research laboratory, St. Joseph's College, Irinjlalakuda. These untreated larvae were also used in larval bioassay as laboratory strain.

\subsection{Larval Bioassay}

The standard World Health Organization (WHO) procedure was followed for determining larval susceptibility [31]. Accordingly, the larvae were subjected to different concentrations of insecticides whose stock solutions were prepared using distilled water as the solvent. $1 \mathrm{mg} / \mathrm{ml}$ deltamethrin, lambda-cyhalothrin, and malathion stock solution was prepared in water. Test concentrations were prepared by adding $1 \mathrm{ml}$ insecticide-containing solution to 249 $\mathrm{ml}$ of water in a $500 \mathrm{ml}$ capacity beaker and stirred vigorously for 30 seconds with a glass stirrer. For the control, $1 \mathrm{ml}$ of distilled water or acetone as required was added to $249 \mathrm{ml}$ of dechlorinated water instead of insecticide. To each of the beakers containing different tests and control, 25 late third or early fourth instar larvae were released with the help of a glass strainer. Six serial test concentrations of insecticides were prepared for larval bioassay. Mortality was recorded after 24 hours. Unmoved and moribund larvae were treated as dead larvae. If 5\%-20\% mortality was obtained in the control experiment, it was corrected by using Abbott's formula [32]. The $\mathrm{LC}_{50}$ and $\mathrm{LC}_{90}$ values for insecticides were calculated using Probit analysis by the dosage mortality regression line [33].

\section{RESULT}

Larvicidal efficacy of malathion, deltamethrin, and lambdacyhalothrin on field-collected and laboratory-reared Ae. albopictus and $C x$. quinquefasciatus is given in Tables 1 and 2. The results of malathion susceptibility of field-collected and laboratory-colonized Ae. albopictus and Cx. quinquefasciatus larvae illustrated that the 
Table 1: Mosquito larvicidal effect of malathion, deltamethrin, and lambda-cyhalothrin against Aedes albopictus.

\begin{tabular}{|c|c|c|c|c|c|}
\hline Insecticide & LC25 (LCL-UCL) & LC50 (LCL-UCL) & LC90 (LCL-UCL) & CHI square value & $p$ value \\
\hline \multicolumn{6}{|l|}{ Field strain } \\
\hline Malathion & $\begin{array}{c}7.4643 \times 10^{-3} \mathrm{ppm}(3.4597 \times \\
\left.10^{-3}-1.0200 \times 10^{-2}\right)\end{array}$ & $\begin{array}{c}1.2398 \times 10^{-2} \mathrm{ppm}(8.6815 \times \\
\left.10^{-3}-1.7250 \times 10^{-2}\right)\end{array}$ & $\begin{array}{c}3.2516 \times 10^{-2} \mathrm{ppm}(2.1659 \times \\
\left.10^{-2}-1.0775 \times 10^{-1}\right)\end{array}$ & 23.362 & $0.000107202^{\mathrm{a}}$ \\
\hline Deltamethrin & $\begin{array}{c}6.4881 \times 10^{-4} \mathrm{ppm}(4.5221 \times \\
\left.10^{-4}-8.0519 \times 10^{-4}\right)\end{array}$ & $\begin{array}{c}1.0249 \times 10^{-3} \mathrm{ppm}(8.3082 \times \\
\left.10^{-4}-1.2185 \times 10^{-3}\right)\end{array}$ & $\begin{array}{c}2.4435 \times 10^{-3} \mathrm{ppm}(1.9358 \times \\
\left.10^{-3}-3.6504 \times 10^{-3}\right)\end{array}$ & 9.709 & $0.045634782^{\mathrm{a}}$ \\
\hline Lambda-Cyhalothrin & $\begin{array}{c}5.3587 \times 10^{-4} \mathrm{ppm}(3.2222 \times \\
\left.10^{-4}-7.0675 \times 10^{-4}\right)\end{array}$ & $\begin{array}{c}9.0259 \times 10^{-4} \mathrm{ppm}(6.7797 \times \\
\left.10^{-4}-1.13 .6 \times 10^{-3}\right)\end{array}$ & $\begin{array}{c}2.4305 \times 10^{-3} \mathrm{ppm}(1.8091 \times \\
\left.10^{-3}-4.2521 \times 10^{-3}\right)\end{array}$ & 12.671 & $0.013001896^{\mathrm{a}}$ \\
\hline Malathion & $\begin{array}{c}1.1442 \times 10^{-3} \mathrm{ppm}(5.1524 \times \\
\left.10^{-4}-1.5676 \times 10^{-3}\right)\end{array}$ & $\begin{array}{c}1.8672 \times 10^{-3} \mathrm{ppm}(1.2904 \times \\
\left.10^{-3}-2.6246 \times 10^{-3}\right)\end{array}$ & $\begin{array}{c}4.7353 \times 10^{-3} \mathrm{ppm}(3.1612 \times \\
\left.10^{-3}-1.6322 \times 10^{-2}\right)\end{array}$ & 25.735 & $0.00003579^{\mathrm{a}}$ \\
\hline Deltamethrin & $\begin{array}{c}4.3115 \times 10^{-5} \mathrm{ppm}(1.86603 \times \\
\left.10^{-5}-6.46454 \times 10^{-5}\right)\end{array}$ & $\begin{array}{c}8.7237 \times 10^{-5} \mathrm{ppm}(5.5912 \times \\
\left.10^{-5}-1.2074 \times 10^{-4}\right)\end{array}$ & $\begin{array}{c}3.3284 \times 10^{-4} \mathrm{ppm}(2.1763 \times \\
\left.10^{-4}-8.1799 \times 10^{-4}\right)\end{array}$ & 14.853 & $0.005^{\mathrm{a}}$ \\
\hline Lambda-Cyhalothrin & $\begin{array}{c}2.3138 \times 10^{-5} \mathrm{ppm}(8.3473 \times \\
\left.10^{-6}-3.6602 \times 10^{-5}\right)\end{array}$ & $\begin{array}{c}4.9158 \times 10^{-5} \mathrm{ppm}(2.8954 \times \\
\left.10^{-5}-7.1322 \times 10^{-5}\right)\end{array}$ & $\begin{array}{c}2.0578 \times 10^{-4} \mathrm{ppm}(1.2750 \times \\
\left.10^{-4}-6.1128 \times 10^{-4}\right)\end{array}$ & 17.003 & $0.002^{\mathrm{a}}$ \\
\hline
\end{tabular}

Table 2: Mosquito larvicidal effect of malathion, deltamethrin, and lambda-cyhalothrin against Culex quinquefasciatus.

\begin{tabular}{|c|c|c|c|c|c|}
\hline Insecticide & LC25 (LCL-UCL) & LC50 (LCL-UCL) & LC90 (LCL-UCL) & CHI square value & $p$ value \\
\hline \multicolumn{6}{|l|}{ Field strain } \\
\hline Malathion & $\begin{array}{c}1.5 \times 10-2 \underset{\times p m}{\operatorname{ppm}(8} \times 10-3-2 \\
\times 0-1)\end{array}$ & $\begin{array}{c}2.6 \times 10^{-2} \operatorname{ppm}\left(1.9 \times 10^{-2}-3.3\right. \\
\left.\times 10^{-2}\right)\end{array}$ & $\begin{array}{c}7.3 \times 10^{-2} \mathrm{ppm}\left(5.3 \times 10^{-2}-1.38\right. \\
\left.\times 10^{-1}\right)\end{array}$ & 14.010 & $0.007^{\mathrm{a}}$ \\
\hline Deltamethrin & $\begin{array}{c}1.2482 \times 10-3 \mathrm{ppm}(7.869 \times \\
10-4-1.5796 \times 10-3)\end{array}$ & $\begin{array}{c}1.9125 \times 10^{-3} \mathrm{ppm}(1.4928 \times \\
\left.10^{-3}-2.3853 \times 10^{-3}\right)\end{array}$ & $\begin{array}{c}4.3021 \times 10^{-3} \mathrm{ppm}(3.2180 \times \\
\left.10^{-3}-8.1746 \times 10^{-3}\right)\end{array}$ & 16.778 & $0.002134925^{\mathrm{a}}$ \\
\hline Lambda-Cyhalothrin & $\begin{array}{c}1.2360 \times 10-3 \mathrm{ppm}(7.5425 \times \\
10-4-1.5784 \times 10-3)\end{array}$ & $\begin{array}{c}1.9052 \times 10^{-3} \mathrm{ppm}(1.4675 \times \\
\left.10^{-3}-2.4018 \times 10^{-3}\right)\end{array}$ & $\begin{array}{c}4.3345 \times 10^{-3} \mathrm{ppm}(3.2060 \times \\
\left.10^{-3}-8.6456 \times 10^{-3}\right)\end{array}$ & 17.828 & $0.00133342^{\mathrm{a}}$ \\
\hline Malathion & $\begin{array}{c}2.7717 \times 10^{-3} \mathrm{ppm}(1.6451 \times \\
\left.10^{-4}-5.1244 \times 10^{-3}\right)\end{array}$ & $\begin{array}{c}5.7159 \times 10^{-3} \mathrm{ppm}(1.8352 \times \\
\left.10^{-3}-1.1258 \times 10^{-2}\right)\end{array}$ & $\begin{array}{c}2.2612 \times 10^{-2} \mathrm{ppm}(1.1416 \times \\
\left.10^{-2}-7.8949 \times 10^{-1}\right)\end{array}$ & 44.394 & $0.000000005^{\mathrm{a}}$ \\
\hline Deltamethrin & $\begin{array}{c}1.0272 \times 10^{-4} \mathrm{ppm}(7.45144 \times \\
\left.10^{-5}-1.228286 \times 10^{-4}\right)\end{array}$ & $\begin{array}{c}1.4540 \times 10^{-4} \mathrm{ppm}(1.2131 \times \\
\left.10^{-4}-1.7020 \times 10^{-4}\right)\end{array}$ & $\begin{array}{c}2.8138 \times 10^{-4} \mathrm{ppm}(2.277889 \times \\
\left.10^{-4}-4.253177 \times 10^{-4}\right)\end{array}$ & 13.518 & $0.009002003^{\mathrm{a}}$ \\
\hline Lambda-Cyhalothrin & $\begin{array}{c}9.8709 \times 10^{-5} \mathrm{ppm}(5.99641 \times \\
\left.10^{-5}-1.2622 \times 10^{-4}\right)\end{array}$ & $\begin{array}{c}1.5090 \times 10^{-4} \mathrm{ppm}(1.1552 \times \\
\left.10^{-4}-1.884708 \times 10^{-4}\right)\end{array}$ & $\begin{array}{c}3.3806 \times 10^{-4} \mathrm{ppm}(2.5384 \times \\
\left.10^{-4}-6.386195 \times 10^{-4}\right)\end{array}$ & 17.740 & $0.001^{\mathrm{a}}$ \\
\hline
\end{tabular}

$\mathrm{LCL}=$ lower confidence limit; $\mathrm{UCL}=$ upper confidence limit.

$p$-value $<0.05$ shows a significant difference at $5 \%$.

laboratory strain was more susceptible than field-collected strain. The $\mathrm{LC}_{50}$ value of field-collected Ae. albopictus was $1.2398 \times 10^{-2}$ ppm, which was about 6.64 times greater than the laboratory strain whose $\mathrm{LC}_{50}$ was $1.8672 \times 10^{-3} \mathrm{ppm} . \mathrm{LC}_{50}$ value of field-collected Cx. quinquefasciatus $2.6 \times 10^{-2} \mathrm{ppm}$ and $\mathrm{LC}_{50}$ of laboratory strain was $5.7159 \times 10^{-3} \mathrm{ppm}$.

Deltamethrin susceptibility result displayed that the $\mathrm{LC}_{50}$ value of field-collected Ae. albopictus was $1.0249 \times 10^{-3} \mathrm{ppm}$ and laboratory strain Ae. albopictus was $8.7237 \times 10^{-5} \mathrm{ppm}$. $\mathrm{LC}_{50}$ value of field strain $C x$. quinquefasciatus was $1.9125 \times 10^{-3} \mathrm{ppm}$, and that of laboratory strain was $1.4540 \times 10^{-4}$. Susceptibility results of lambda-cyhalothrin indicated that the laboratory strain was more susceptible than field strain. $\mathrm{LC}_{50}$ of field-collected Ae. albopictus $9.0559 \times 10^{-4} \mathrm{ppm}$ and $\mathrm{LC}_{50}$ of laboratory strain was $4.91589 \times$ $10^{-5} \mathrm{ppm} . \mathrm{LC}_{50}$ of field-collected $C x$. quinquefasciatus was 1.9052 $\times 10^{-3} \mathrm{ppm}$ and $\mathrm{LC}_{50}$ of laboratory strain $C x$. quinquefasciatus was $1.5090 \times 10^{-4}$
Ae. albopictus mosquitoes exhibited more susceptibility than $C x$. quinquefasciatus, and both field and laboratory strains of all three groups were treated by three different insecticides.

Figures 1-3 show the comparison of susceptibility status of field and laboratory strains of Ae. albopictus and Cx. quinquefasciatus against three different insecticides. Lambda-cyhalothrin was the most efficient insecticide, and malathion showed the least efficacy when compared to the other two insecticides used. All mosquitoes showed more susceptibility toward lambda-cyhalothrin and less toward malathion. The susceptibility rate can be illustrated in the order of lambda-cyhalothrin $>$ deltamethrin $>$ malathion.

\section{DISCUSSION}

Organochlorines, organophosphates, carbamates, and pyrethroids are the widespread chemical compounds used in the pest control strategy. Altogether, 12 different insecticides belonging to these four classes were recommended by the WHO for mosquito 
Log of Concentration v/s Percentage mortality plot of Deltamethrin against field and laboratory strain of Ae.albopictus and Cx.quinquefasciatus

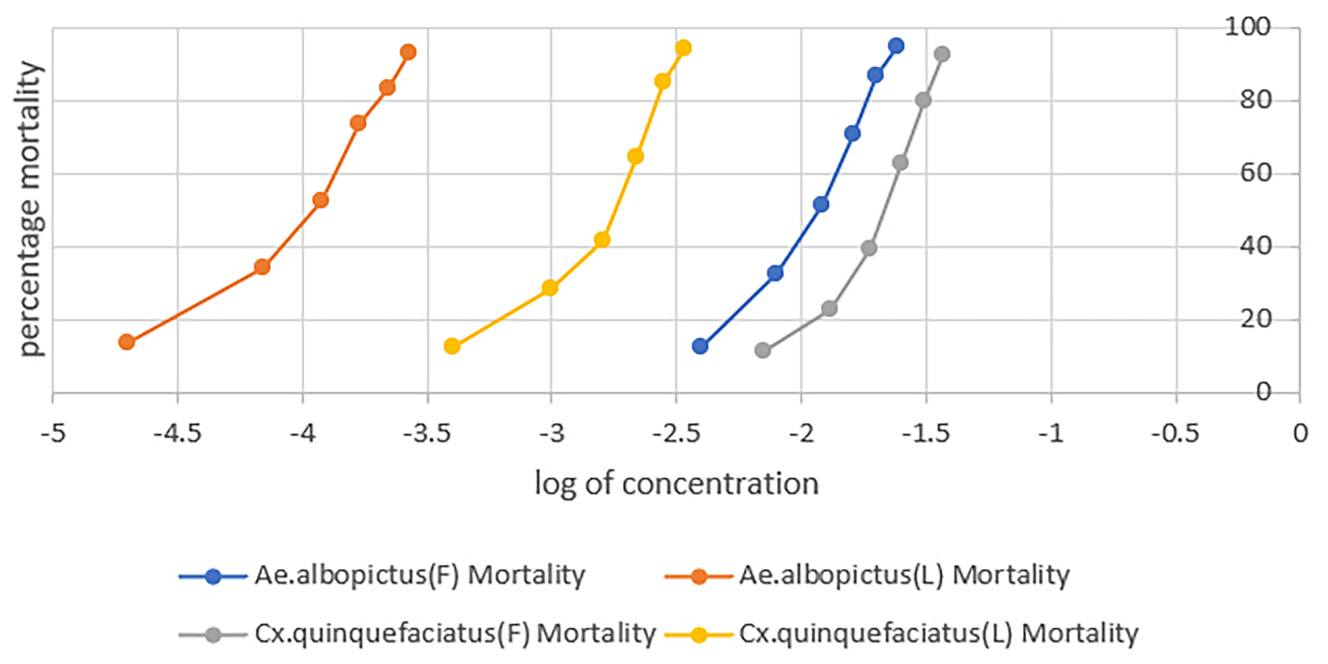

Figure 1: Comparison of susceptibility status of deltamethrin against laboratory and field strains of Ae. albopictus and Cx. quinquefasciatus.

Log of Concentration v/s Percentage mortality plot of Lamda-cyhalothrin against field and laboratory strain of Ae.albopictus and Cx.quinquefasciatus

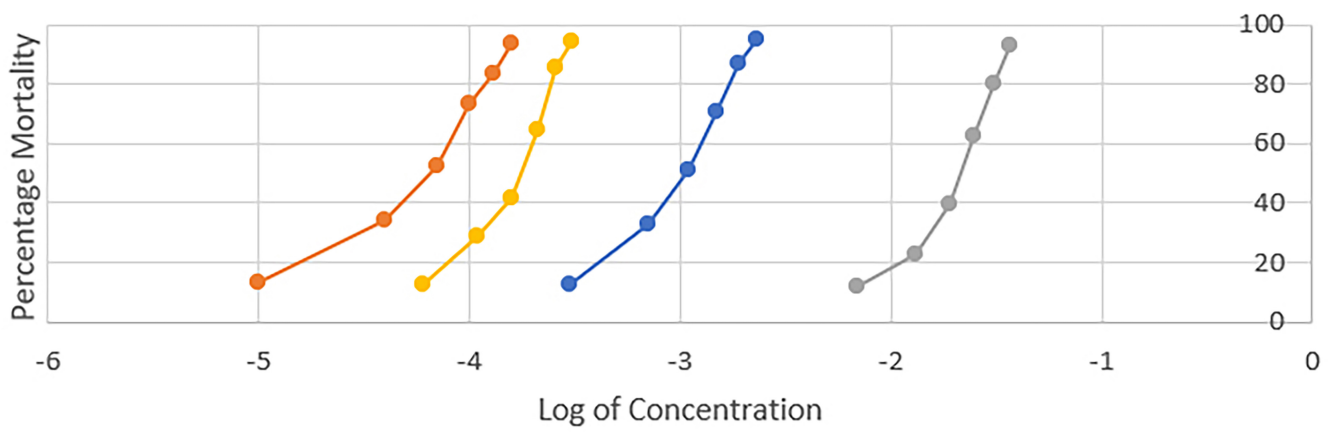

$\longrightarrow$ Ae.albopictus(F) Mortality $\longrightarrow$ Ae.albopictus(L) Mortality
$\longrightarrow$ Cx.quinquefaciatus(F) Mortality $\longrightarrow$ Cx.quinquefaciatus(L) Mortality

Figure 2: Comparison of susceptibility status of lambda-cyhalothrin against laboratory and field strains of Ae. albopictus and Cx. quinquefasciatus.

eradication [34,35]. Malathion comes under the organophosphate group of insecticides, is lethal to insects at the same time, and is less harmful to mammals. These second-generation insecticides are globally used for mosquito control only after the prohibition of Dichlorodiphenyltrichloroethane and dieldrin in the USA in the 1970s [24]. The extensive use of malathion arose from some resistance problems in different mosquito species worldwide, and several researchers also conducted many studies. Our present study discloses that laboratory strain Ae. albopictus and $C x$. quinquefasciatus more susceptible than the field stain, which was collected from Thrissur Kole wetlands. Studies on malathion resistance against mosquitoes were reported in the 1990s itself. Bisset et al. [36] and Bracco et al. [37] reported on malathion and carbamate resistance in Cx. quinquefasciatus in Cuba And Brazil, respectively. In 2010, Selvi et al. [38] discussed their result in the study on the susceptibility of Ae. albopictus in against malathion. They discovered that the laboratory strain mosquitoes were more susceptible than field strain ones because of the recurrent contact with the insecticides used in the field. Organophosphate, carbamate, and pyrethroid resistance were also noted in $C x$. quinquefasciatus mosquito by some studies conducted in America, Saudi Arabia, and northern Thailand [39-41]. 
Log of Concentration v/s Percentage mortality plot of Malathion against field and laboratory strain of Ae.albopictus and Cx.quinquefasciatus
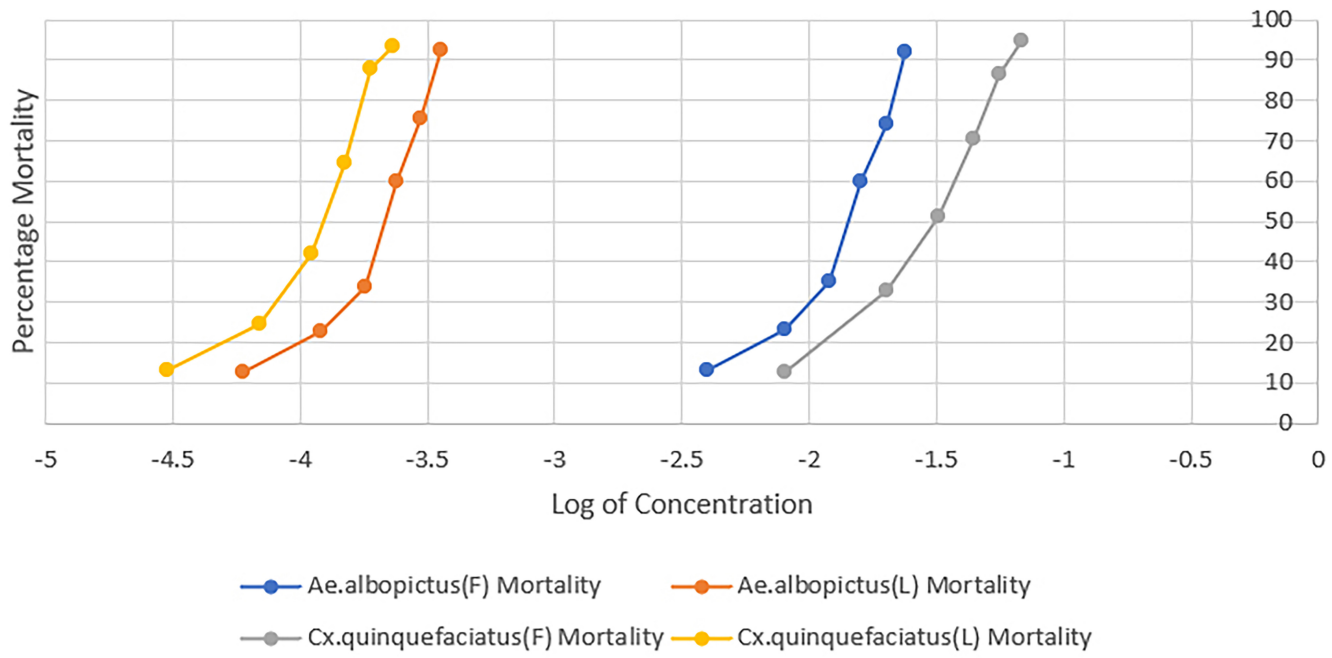

Figure 3: Comparison of susceptibility status of malathion against laboratory and field strains of Ae. albopictus and Cx. quinquefasciatus.

Kole wetlands is the major rainwater plunked ground of the surrounding area of the Thrissur district. Karuvannur and Kecheri river sediments urban and industrial atrophies with their monsoon flood watercourse to this delta every year [42]. Tessy and Sreekumar [43] reported almost 30 pollutant tolerant algal species from Thrissur Kole wetlands. Our study site is considered one of Kerala's major rice bowls, and the paddy cultivation practices take place during northeast monsoon season to post-monsoon season (September-March). An enormous number of pesticides, weedicides, and fertilizers have been applied by the farmers in these paddy fields to protect their crops and attain maximum yield $[44,45]$. These chemical combinations bring about some insecticidal tolerance in different mosquito species and other non-targeted organisms. Two individual studies publicized such tolerance in Ae. albopictus and Ae. aegypti, respectively [46,47].

In the current study, we made a comparative analysis of field-collected and laboratory-colonized Ae. albopictus and Cx.quinquefasciatus mosquitoes against malathion, deltamethrin, and lambda-cyhalothrin. Laboratory strains of Ae. albopictus and $C x$. quinquefasciatus were more susceptible than the field strains. The outcome unveiled that both Ae. albopictus and Cx. quinquefasciatus exhibit more susceptibility toward lambda-cyhalothrin and least susceptible toward malathion. The susceptibility rate is in the order of lambda-cyhalothrin $>$ deltamethrin $>$ malathion in these mosquitoes. Hamdan et al. [48] discovered some $\mathrm{LC}_{50}$ values in Ae. albopictus and Cx. quinquefasciatus mosquitoes. The result of Ae.albopictus susceptibility test showed $\mathrm{LC}_{50}$ of malathion is $0.1972 \mathrm{ppm}$, temephos is $0.0514 \mathrm{ppm}$, and permethrin is 0.0022 ppm. The LC value in $C x$. quinquefasciatus against malathion is $0.0163 \mathrm{ppm}$ and permethrin is $0.00001 \mathrm{ppm}$. The result indicates that Ae.albopictus is more susceptible than $C x$. quinquefasciatus toward all the insecticides tested and could explain the natural larval habitat preference of Culex mosquitoes is more polluted larval habitats when compared to Aedes species which breeds in freshwater.
Aedes mosquitoes generally adopt freshwater habitats and Culex prefers slightly to immensely polluted water for their development. The present study perceived that both species were collected from the same environment, which indicates that these mosquitoes had developed some resistance. The susceptibility assays conducted against different commonly used insecticides in the pest control study area also support these findings. Results from the quantitative susceptibility assays demonstrate the variance between the field and laboratory strains, in which field strains showed more resistance toward all the tested insecticides. The field strain of Ae. albopictus showed 6.36, 11.74, and 18.36 times more resistance than the laboratory strain against malathion, deltamethrin, and lambda-cyhalothrin, respectively. $C x$. quinquefasciatus larvae followed this resistance pattern with 4.54 times resistance against malathion and 13.15 times and 12.62 times resistance against deltamethrin and lambdacyhalothrin, correspondingly. A study conducted in Thailand observed such resistance array in $C x$. quinquefasciatus against a group of insecticides, and they suggested that the prevalent interaction of insecticides might have resulted in some resistance in these mosquitoes [49]. The remarkable difference of $\mathrm{LC}_{50}$ values between the same species' strains might result from their resistance development to the insecticides, and this trait could be considered a crucial characteristic of a biological indicator of insecticide pollution. There are some early remarks on mosquitoes as possible bioindicators of insecticide pollution [50], and some recent surveys justified Culex mosquitoes as lead effluence bioindicators [51]. The utilization of the study area for seasonal paddy cultivation and periodical exposure to the mentioned chemical insecticides for insect pest management makes this study's findings more significant [45].

\section{CONCLUSION}

Various chemical insecticides have been used for decades in agricultural as well as public health indices to improve crop 
productivity and accomplish better mosquito management. However, overdependence and disproportionate use of these chemical insecticides are primarily attributed to the development of resistance in targeted organisms. Mosquitoes collected from the areas contaminated with extensive chemical exposure showed some insecticidal tolerance. Subordinate part of this unsystematic usage is environmental effluence and harmful effects on non-targeted organisms. This study tried to discuss some lethal concentration values of two mosquitoes against three conventional insecticides. These values may help to contribute toward efficiency in mosquito-monitoring tactics with a minimal ecosystem imbalance.

\section{AKNOWLEDGEMENT}

The authors are thankful to the Principal, St. Joseph's College, Irinjalakuda, Thrissur, Kerala for the laboratory facilities provided. We acknowledge E-grants government of Kerala for providing funds.

\section{REFERENCES}

1. Abraham S. The relevance of wetland conservation in Kerala. Int Fauna Biol Stud 2015;2(3):01-5.

2. Dale PE, Knight JM. Wetlands and mosquitoes: a review. Wetl Ecol Manag 2008;16(4):255-76.

3. Schäfer ML, Lundström JO, Petersson E. Comparison of mosquito (Diptera: Culicidae) populations by wetland type and year in the lower River Dalälven region, Central Sweden. J Vector Ecol 2008;33(1): $150-7$.

4. Srinivasan JT. Understanding the Kole lands in Kerala as a multiple use wetland ecosystem. Research Unit for Livelihoods and Natural Resources, Hyderabad, India, 2010.

5. Dian Z, Changxing S. Sedimentary causes and management of two principal environmental problems in the lower Yellow River. Environ Manage 2001;28(6):749-60.

6. Norris DE. Mosquito-borne diseases as a consequence of land use change. EcoHealth 2004;1(1):19-24.

7. Jang YS, Kim MK, Ahn YJ, Lee HS. Natural products, organic chemistry: larvicidal activity of Brazilian plants against Aedes aegypti and Culex pipiens pallens (Diptera: Culicidae). J Appl Biol Chem 2002;45(3):131-4.

8. Wilder-Smith A, Chen LH, Massad E, Wilson ME. Threat of dengue to blood safety in dengue-endemic countries. Emerg Infect Dis 2009; 15(1):8.

9. Young Su J, Mookey K, Young Joo A. Larvicidal activity of Brazilian plants against Aedes aegypti and Culex pipiens (Dipteral culicindae). Agric Chem 2002;45(3):131-4.

10. Yap HH, Zairi J, Jahangir K, Adanan CR. Culex: mosquitoes that spread Japanese encephalitis. Mosquitoes and mosquito borne diseases. Academic Science Malaysia, Kuala Lumpur, Malaysia, pp 73-9, 2000 .

11. Samuel PP, Arunachalam N, Hiriyan J, Thenmozhi V, Gajanana A, Satyanarayana K. Host-feeding pattern of Culex quinquefasciatus Say and Mansonia annulifera (Theobald) (Diptera: Culicidae), the major vectors of filariasis in a rural area of south India. J Med Entomol 2004;41(3):442-6.

12. Pitzer JB, Byford RL, Vuong HB, Steiner RL, Creamer RJ, Caccamise DF. Potential vectors of West Nile virus in a semiarid environment: Dona Ana County, New mexico. J Med Entomol 2009;46(6):1474-82.

13. Jones SC, Morris J, Hill G, Alderman M, Ratard RC. St. Louis encephalitis outbreak in Louisiana in 2001. J La State Med Soc 2002; 154(6):303-6.

14. Lindsay MD, Broom AK, Wright AT, Johansen CA, Mackenzie JS. Ross river virus isolations from mosquitoes in arid regions of
Western Australia: implication of vertical transmission as a means of persistence of the virus. Am J Trop Med Hyg 1993;49(6):686-96.

15. Nitatpattana $N$, Apiwathnasorn $C$, Barbazan $P$, Leemingsawat $S$, Yoksan S, Gonzalez J. First isolation of Japanese encephalitis from Culex quinquefasciatus in Thailand. SE Asian J Trop Med Public Health 2005;36(4):875.

16. Aneesh EM. Diversity and vectorial capacity of mosquitoes in Kuruva Island, Wayanad District, Kerala, India. J Zool Stud 2014;1(4):16-22.

17. Yap HH, Chong AS, Chong NL, Adanan CR, Malik A, Lim SY. ULV field studies of combined spraying of AQUA RESIGEN and VECTOBAC AS 12 against Aedes aegypti, Aedes albopictus and Culex quinquefasciatus. Trop Biomed1997; 14: 57-63.

18. Invest JF, Lucas JR. Pyriproxyfen as a mosquito larvicide. In Proceedings of the Sixth International Conference on Urban Pests, Budapest, Hungary, 2008, pp 239-45.

19. Ho LY, Zairi J. Species composition and pyrethroid susceptibility status of Anopheles mosquitoes from two different locations in Malaysia. Trop Biomed 2013;30(1):125-30.

20. Karunamoorthi K, Mohammed M, Wassie F. Knowledge and practices of farmers with reference to pesticide management: implications on human health. Arch Environ Occup Health 2012;67(2):109-16.

21. Lengeler $\mathrm{C}$. Insecticide-treated nets for malaria control: real gains Bull World Health Organ 2004;82(2):84.

22. Mabaso ML, Sharp B, Lengeler C. Historical review of malarial control in southern African with emphasis on the use of indoor residual house-spraying. Trop Med Int Health 2004;9(8):846-56.

23. Mittal PK, Wijeyaratne P, Pandey S. Status of insecticide resistance of malaria, Kala-azar and Japanese encephalitis vectors in Bangladesh, Bhutan, India and Nepal (BBIN). Environ Health Project Activity Rep 2004;129:44-8.

24. Prato M, Khadjavi A, Mandili G, Minero VG, Giribaldi G. Insecticides as strategic weapons for malaria vectorcontrol. Insecticides - Advances in Integrated Pest Management. InTech 2012; 91-114.

25. Reigart JR, Roberts JR. Recognition and management of pesticide poisonings. US Environmental Protection Agency, Washington, DC, 1999.

26. Chareonviriyaphap T, Aum-Aung B, Ratanatham S. Current insecticide resistance patterns in mosquito vectors in Thailand. SE Asian J Trop Med Public Health 1999;30:184-94.

27. World Health Organization. Instructions for determining the susceptibility or resistance of mosquito larvae to insecticides. World Health Organization, Geneva, Switzerland, 1981.

28. Johnkutty I, Venugopal VK. Kole lands of Kerala. Kerala Agricultural University, Thrissur, India, 1993.

29. Nagpal BN, Sharma VP. Indian anophelines. Science Publishers, Inc. Hauppauge, NY, 1995

30. Barraud PJ. A revision of the culicine mosquitoes of India. Part XXIV. The Indian species of the subgenera Skusea and Aedes, with descriptions of eight new species, and remarks on a new method for identifying the females of the subgenus Aedes. Indian J Med Res 1928;16:368-9.

31. Brown AW, Pal R. Insecticide resistance in arthropods. World Health Organization, Geneva, Switzerland, 1971.

32. Abbott WS. A method of computing the effectiveness of an insecticide. J Econ Entomol 1925;18(2):265-7.

33. Finney DJ. Probit analysis. 3rd edition, Cambridge University Press, Cambridge, UK, 1971.

34. Marcombe S, Poupardin R, Darriet F, Reynaud S, Bonnet J, Strode $\mathrm{C}$, et al. Exploring the molecular basis of insecticide resistance in the dengue vector Aedes aegypti: a case study in Martinique Island (French West Indies). BMC Genomics 2009;10(1):494.

35. World Health Organization, Special Programme for Research, Training in Tropical Diseases, World Health Organization. Department of control of neglected tropical diseases, World Health Organization. Epidemic, pandemic alert. Dengue: guidelines for diagnosis, treatment, prevention and control. World Health Organization, Geneva, Switzerland, 2009. 
36. Bisset JA, Rodriguez MM, Dayami L. Determination of resistance mechanism in Culex quinquefasciatus Say 1823 and its operational implication in the correct use of insecticides for its control. Rev Cubana Med Trop 1994;46(2):108-14.

37. Bracco JE, Dalbon M, Marinotti O, Barata JM. Resistance to organophosphorous and carbamates insecticides in a population of Culex quinquefasciatus. Rev Saude Publica 1997;31(2):182-3.

38. Selvi S, Edah MA, Nazni WA, Lee HL, Tyagi BK, Sofian-Azirun M, et al. Insecticide susceptibility and resistance development in malathion selected Aedes albopictus (Skuse). Trop Biomed 2010;27(3):534-50.

39. Georghiou GP, Pasteur N, Hawley MK. Linkage relationships between organophosphate resistance and a highly active esterase-B in Culex quinquefasciatus from California. J Econ Entomol 1980;73(2):301-5.

40. Amin AM, Peiris HT. Detection and selection of organophosphate and carbamate resistance in Culex quinquefasciatus from Saudi Arabia. Med Vet Entomol 1990;4(3):269-73.

41. Somboon P, Prapanthadara LA, Suwonkerd W. Insecticide susceptibility tests of Anopheles minimus s.1., Aedes aegypti, Aedes albopictus, and Culex quinquefasciatus in northern Thailand. SE Asian J Trop Med Public Health 2003;34(1):87-93.

42. Binilkumar AS, Ramanathan A. Valuing Stakeholder preferences on improved conservation and management of Kol Wetland: a contingent valuation study. A Conference on Ecosystem Services (ACES), Bonita Springs, FL, 2008.

43. Tessy PP, Sreekumar R. A report on the pollution algae from the Thrissur Kol wetlands (part of Vembanad Kol, Ramsar site), Kerala. Nat Environ Pollut Technol 2008;7(2):311.

44. Impact of Pesticides and Fertilizers on Quality of Water in Wetlands (Kole) and Neighbouring areas of Division 43 of Thrissur Corporation. St. Aloysius College, Elthuruth, Thrissur, Kerala, 2016.

45. Srinivasan JT. An economic analysis of paddy cultivation in the Kole land of Kerala. Indian J Agric Econ 2012;67(2):213.
46. Suwanchaichinda C, Brattsten LB. Effects of exposure to pesticides on carbaryl toxicity and cytochrome P450 activities in Aedes albopictus larvae (Diptera: Culicidae). Pestic Biochem Phys 2001;70(2):63-73.

47. Riaz MA, Poupardin R, Reynaud S, Strode C, Ranson H, David JP. Impact of glyphosate and benzo [a] pyrene on the tolerance of mosquito larvae to chemical insecticides. Role of detoxification genes in response to xenobiotics. Aquat Toxicol 2009;93(1):61-9.

48. Hamdan H, Sofian-Azirun M, Nazni WA, Lee HL. Insecticide resistance development in Culex quinquefasciatus (Say), Aedes aegypti (L.) and Aedes albopictus (Skuse) larvae against malathion, permethrin and temephos. Trop Biomed 2005;22(1):45-52.

49. Sathantriphop S, Paeporn P, Supaphathom K. Detection of insecticides resistance status in Culex quinquefasciatus and Aedes aegypti to four major groups of insecticides. Trop Biomed 2006;23(1):97-101.

50. Wielgolaski FE. Biological indicators on pollution. Urban Ecol 1975;1(1):63-79.

51. Kitvatanachai S, Apiwathnasorn C, Leemingsawat S, Wongwit W, Overgaard HJ. Lead levels of Culex mosquito larvae inhabiting lead utilizing factory. Asian Pac J Trop Biomed 2011;1(1):64-8.

\section{How to cite this article:}

Asha A V, Lakshmi K V, Sudhikumar A V, Aneesh E M. Mosquitoes as pesticide pollution Indicators: A comparative susceptibility analysis of field and laboratory strains of mosquitoes against different conventional insecticides. J Appl Biol Biotech 2021; 9(06):115-121. 